\title{
Effects of job stress and coping behaviour on job satisfaction in Korean male nurses
}

\author{
Se-Won Kang ${ }^{1}$, Young-Mi Kim² \\ 1. College of Nursing and Healthcare Science, Dong-Eui University, Busan, South Korea. 2. Emergency Department, \\ Dong-Eui Hospital, Busan, South Korea
}

Correspondence: Se-Won Kang. Address: College of Nursing and Healthcare Science, Dong-Eui University, 995 Eomgwangno, Jin-gu, Busan 614-714, South Korea. Email: swkang75@hotmail.com

Received: January 18, 2014

DOI : 10.5430/jnep.v4n11p66
Accepted: August 31, $2014 \quad$ Online Published: September 10, 2014

URL: http://dx.doi.org/10.5430/jnep.v4n11p66

\section{Abstract}

Purpose: The purpose of this study was to investigate the effects of job stress and coping behaviour on job satisfaction in Korean male nurses.

Methods: The structured questionnaires were used for the survey of 73 male nurses who worked in hospitals located in B and S City in South Korea. To measure job stress, we used a Korean job stress scale. To measure coping behaviour, we used an instrument developed by Han \& Oh (1990), and for job satisfaction, an instrument developed by Kim (2010). The data were analysed using PASW 18.0 (Chicago, USA), including descriptive statistics, independent sample t-tests, and ANOVAs.

Results: The results showed mean job stress score of 3.27, mean coping behaviour score of 3.14 and mean job satisfaction score of 3.28 (all scores on a 5-point scale). Job satisfaction was positively correlated with coping behaviour $(r=0.426, p$ $<.001$ ), but was not correlated with job stress. In addition, job satisfaction was higher among subjects with coping behaviour scores in the highest quartile than among those with coping behaviour scores in the lowest quartile $(t=-2.881, p$ $=.007)$.

Conclusion: Coping behaviour was found to be a relevant factor influencing the job satisfaction of male nurses. Thus, an environment and workplace culture that allows male nurses to develop and apply their coping ability must be cultivated in order to promote job satisfaction.

\section{Key words}

Job stress, Coping, Job satisfaction, Male nurse

\section{I ntroduction}

There has recently been a surge in the demand for medical care due to social trends such as the diversification of the population structure, increased awareness of entitlement, and changes in the social system. This has been accompanied by a rising demand for nursing manpower. Nurses, who are the largest professional workforce in hospitals, have become an essential factor in improving the efficiency and competitiveness of hospitals. 
Recently, a growing number of male students have been applying to nursing departments in universities amidst increased unemployment and a social trend towards the selection of jobs that match the aptitude of applicants regardless of gender stereotypes. This can be attributed to increased flexibility in attitudes towards various occupations and the expansion of perception towards occupational professionalism ${ }^{[1]}$. As a result, the number of male nurses has increased. In Korea, there are 6,202 male nurses, accounting for $2.0 \%$ of 308,620 licensed nurses. The number of licensed male nurses has increased continuously over the last five years, reaching 829 in 2004, 1,292 in 2006, 2,128 in 2008, 3,387 in 2010, and 6,202 in 2013. Four thousand seventy four male nurses have obtained licenses in the last five years accounting for $66 \%$ of all male nurses ${ }^{[2]}$. Perspectives toward gender roles remain conservative in Korea. Such an increase in the number of male nurses represents a significant change in the nursing sector, especially considering that gender stereotypes have traditionally had a great influence on job selection. This large number of newly licensed male nurses represented a valuable human resource that can meet a variety of nursing needs and improve of the quality of medical care. The increased presence of men in the nursing field may also lead to the elimination of prejudicial beliefs that nursing is a female occupation and the reduction of administrative and economic disadvantage arising from gender discrimination in hospitals ${ }^{[3-5]}$.

Although an increasing number of men select careers in nursing for the aforementioned reasons, the number of men dropping out of the nursing field is also growing. Reasons for this include inadequate salaries, lack of opportunities for promotion, problematic relationships with colleagues of the opposite sex, confusion over the role of male nurses, and lack of opportunities for self-development ${ }^{[6-8]}$.

Conflicts result from uncertainty over the roles, obligations, and responsibilities of male nurses; lack of understanding on the part of the patients and medical staff; and employment status of hospital, especially when there is an inadequate perception towards the job of male nurses that comes under the category of professional occupation. Under such circumstances, male nurses are likely to have low job satisfaction and sometimes consider quitting despite the possibility that their professional skills can improve. In addition, women are far better positioned in the nursing sector than their male counterparts, dominating this occupation. The steady increase in the number of male nurses has brought many difficulties associated with their minority status as they engage in work that has traditionally been considered a job only for women ${ }^{[9-11]}$. Thus, it is necessary to increase the job satisfaction of male nurses in order to ensure that they can provide satisfactory care to patients.

Studies on job stress, coping behaviour, and job satisfaction have been conducted in many different areas of nursing. A study conducted among operating room nurses in Taiwan ${ }^{[12]}$ found that job satisfaction had a negative relationship with destructive coping strategies and with job stress. In addition, a study on Australian nurses found that coping strategies appeared to have a mediating effect on job satisfaction and stress resulting from organizational changes ${ }^{[13]}$. Moreover, a study conducted among Turkish nurses ${ }^{[14]}$ found that high job satisfaction was strongly related to positive coping strategies. Studies have investigated various demographic characteristics associated with job satisfaction and related factors among Chinese hospital and ICU nurses ${ }^{[15,16]}$. Although some studies have examined the job or role stress of male nurses ${ }^{[17,18]}$, few have investigated the specific relationship among job satisfaction, job stress, and coping behaviour.

Many studies on male nurses have been conducted worldwide, using both qualitative and quantitative methods, but research in this field remains at an inchoate stage in Korea. Previous studies on men in the nursing profession have focused on topics such as gender stereotypes and the work experience ${ }^{[19,20]}$ and job satisfaction ${ }^{[21]}$ of male nurses. Further research is needed to determine how job satisfaction among male nurses can be improved.

\section{Purpose}

This study investigates the relationship among job stress, coping behaviour, and job satisfaction in male nurses in Korea with a specific focus on the effects of job stress and coping behaviour on job satisfaction. By identifying factors related to job satisfaction in male nurses, this study aims to provide basic data necessary for maintaining the quality of the nursing workforce and ensuring efficient management of human resources in order to ensure that male nurses can have a greater 
sense of accomplishment and job satisfaction in the workplace. The specific objectives are as follows: (1) measure the levels of job stress, coping behaviour, and job satisfaction in male nurses; (2) determine the effects of job stress and coping behaviour on job satisfaction.

\section{Subjects and methods}

\subsection{Design, setting and participants}

This is a descriptive study intended to measure the extent of job stress, coping behaviour, and job satisfaction in male nurses in Korea and examine the effect of job stress and coping behaviour on job satisfaction. The subjects were male nurses working in hospitals with more than 300 beds located in 'B' city and ' $S$ ' city, South Korea. Data collection was carried out from June to August 2012. Subjects were recruited using the snowball sampling method, in which existing subjects recruit new subjects. A structured questionnaire consisted of questions regarding demographic characteristics, job stress, coping behaviour, and job satisfaction. The questionnaire took approximately 10-15 minutes to complete.

\subsection{Ethical considerations}

Approval was obtained from the nursing department at a general and teaching hospital. In accordance with guidelines for the protection of human subjects, the purpose and procedure of the study were explained to the subjects by a researcher. Participants gave informed consent prior to participating in the study. All participant information was processed anonymously.

\subsection{Measurements}

Demographic characteristics: The questionnaire used to collect information on demographic characteristics consisted of 8 items regarding participants' age, marital status, type of work, years of work experience, type of shift work, assigned department, type of hospital, and their reason for choosing to be a nurse.

Job stress: This study used the tool developed by Kim (2010) ${ }^{[22]}$ who modified Korean job stress tool created by Chang et al. $2005^{[23]}$. The questionnaire consisted of 40 questions measuring 7 subfactors: job requirements, relationship conflict, organizational structure, inappropriate reward, autonomy of job, masculine sexual characteristics, and occupational instability. Subjects recorded their responses to each item on a 5-point Likert scale, ranging from '5', indicating 'completely agree' to ' 1 ', indicating 'completely disagree'. Higher scores represent more severe job stress. Cronbach's alpha, an indicator of reliability, was 0.931 for this instrument.

Coping behavior: This study used an instrument developed by Han \& Oh (1990) ${ }^{[24]}$, who translated and modified an instrument created by Lasarus \& Folkman $(1984)^{[25]}$, to measure coping behaviour. This instrument consisted of 29 items measuring 6 factors: problem-oriented behaviour ( 7 items), hope/expectation (4 items), disinterest (4 items), social support (7 items), positive viewpoint (4 items), and release of tension (3 items). Subjects recorded their responses to each item on a 5 -point Likert scale, ranging from ' 5 ', indicating 'completely agree' to ' 1 ', indicating 'completely disagree'. Higher scores represent better coping behaviour. Cronbach's alpha was 0.805 for this instrument.

Job satisfaction: This study used an instrument developed by Kim $(2010)^{[22]}$, who translated and modified an instrument created by Slavitt, Stamps, Piedmont, \& Haase $(1978)^{[26]}$. This instrument consisted of 26 items measuring 7 factors: occupation, remuneration, organizational characteristics, interaction, job requirements, autonomy, and relationship with physicians. Items were scored on 5-point likert scale. Subjects recorded their responses to each item on a 5-point Likert scale, ranging from ' 5 ', indicating 'completely agree' to ' 1 ', indicating 'completely disagree'. Higher scores represent greater job satisfaction. Cronbach's alpha was 0.891 for this instrument. 


\subsection{Statistical analyses}

The data were analyzed by PASW 18.0 (Chicago, USA). General characteristics and scores on measures of job stress, coping behaviour, and job satisfaction were analyzed by percentage, mean value, and standard deviation. Differences in scores between groups defined by general characteristics were analyzed using an independent sample $t$-test or ANOVA. Scheffe test was used for post-hoc comparisons. Relationships between variable were analyzed with Pearson's correlation. Differences in job satisfaction between the highest- and lowest-scoring quartiles (representing the highest and lowest $25 \%$ of scorers, respectively) with regard to job stress and coping behaviour were analyzed using the independent samples $t$-test. The significance level of the data was verified at the level of $p<.05$.

\section{Results}

\subsection{General characteristics of participants, job stress, coping behaviour, and job satisfaction}

The sample included in this study consisted of 73 male nurses. The average age of subjects was 27.8. Those who were unmarried accounted for $83.6 \%$. Staff nurses comprised $80.8 \%$. Those with more than 2 years of experience accounted for $16.4 \%$. In regard to type of work-shift, $79.5 \%$ were working on a shift basis. Subjects were employed in a variety of departments, with $35.6 \%$ working in intensive care units and $26.0 \%$ working in emergency rooms. Regarding the type of hospital where subjects worked, $37.0 \%$ worked in tertiary hospitals (university hospitals), while $63.0 \%$ worked in secondary and primary hospitals (district hospitals). Regarding subjects' motivation for choosing to work as nurses, $47.9 \%$ cited job stability, while $31.5 \%$ were motivated by job expertise.

Participants had mean scores of $3.27 \pm 0.55$ in job stress, $3.14 \pm 0.46$ in coping behaviour and $3.28 \pm 0.36$ in job satisfaction (all ranges: 1-5; see Table 1).

No general participant characteristics were significantly related to job stress scores, but some relationships were observed between various general participant characteristics and coping behaviour or job satisfaction. Higher coping behaviour scores were found in subjects who were married than in those who were unmarried $(3.50 \pm 0.48>3.24 \pm 0.32, t=-2.308$, $p=.024)$. Job satisfaction was higher in staff nurses than in the nurse specialists or physician assistants $(3.21 \pm 0.46>2.85$ $\pm 0.33, t=2.309, p=.024)$. There was also a difference in job satisfaction according to type of work-shift. Subjects working on a 3-shift basis had higher job satisfaction than those holding full-time positions (not working shifts) (3.20 \pm $0.46>2.93 \pm 0.37, t=-2.046, p=.044)$. Subjects' motivation for selecting nursing as an occupation was also related to their job satisfaction $(\mathrm{F}=4.676, p=.002)$. In particular, those who chose nursing based on job expertise tended to have higher job satisfaction scores than those who chose nursing because of job stability $(p=.011)$ (see Table 1$)$.

\subsection{Effects of job stress and coping behaviour on job satisfaction}

No correlation was found between job satisfaction and job stress $(r=-0.047, p=.702)$. A positive correlation was observed between job satisfaction and coping behaviour $(r=0.426, p<.001)$ (see Table 2$)$.

Differences in job satisfaction related to job stress and coping behaviour scores were also analyzed by comparing job satisfaction scores in the highest and lowest-scoring quartiles (representing the highest and lowest $25 \%$ of scorers, respectively) in both job stress and coping behaviour. No difference was found in job satisfaction scores between job-stress-score groups $(t=0.042, p=.967)$. A statistically significant difference was found in job satisfaction scores between the two coping-behaviour-score groups $(3.53 \pm 0.53>3.09 \pm 0.37, t=-2.881, p=.007)$ (see Table 3$)$. 
Table 1. General characteristics of participants and scores on job stress, coping behaviour, and job satisfaction

\begin{tabular}{|c|c|c|c|c|c|c|c|}
\hline \multirow[b]{2}{*}{ Variables } & \multirow[b]{2}{*}{${ }^{\dagger} \mathrm{n}(\%)$} & \multicolumn{2}{|l|}{ Job stress } & \multicolumn{2}{|c|}{ Coping behaviour } & \multicolumn{2}{|c|}{ Job satisfaction } \\
\hline & & $\begin{array}{l}\text { Mean(SD) } \\
\text { (range 1-5) }\end{array}$ & $\begin{array}{l}t \text { or F } \\
(p)\end{array}$ & $\begin{array}{l}\text { Mean(SD) } \\
\text { (range 1-5) }\end{array}$ & $\begin{array}{l}t \text { or F } \\
(p)\end{array}$ & $\begin{array}{l}\text { Mean(SD) } \\
\text { (range 1-5) }\end{array}$ & $\begin{array}{l}t \text { or F } \\
\text { (p) }\end{array}$ \\
\hline Total & & $3.27(0.55)$ & & $3.14(0.46)$ & & $3.28(0.36)$ & \\
\hline \multicolumn{8}{|l|}{ Age } \\
\hline$<30$ (years) & $56(76.7)$ & $3.26(0.55)$ & -0.326 & $3.24(0.36)$ & -1.939 & $3.11(0.45)$ & -1.052 \\
\hline$\geq 30$ & $17(23.3)$ & $3.31(0.54)$ & $(.745)$ & $3.43(0.34)$ & $(.057)$ & $3.25(0.48)$ & $(.297)$ \\
\hline \multicolumn{8}{|l|}{ Marriage status } \\
\hline Married & $12(16.4)$ & $3.35(0.67)$ & -0.563 & $3.50(0.48)$ & -2.308 & $3.34(0.62)$ & -1.593 \\
\hline Unmarried & $61(83.6)$ & $3.25(0.58)$ & $(.576)$ & $3.24(0.32)$ & $(.024)^{*}$ & $3.11(0.42)$ & $(.116)$ \\
\hline \multicolumn{8}{|l|}{ Type of work } \\
\hline Staff nurse & $59(80.8)$ & $3.31(0.55)$ & 0.918 & $3.28(0.38)$ & 0.759 & $3.21(0.46)$ & 2.309 \\
\hline Specialist or PA & $14(19.2)$ & $3.14(0.59)$ & $(.362)$ & $3.19(0.25)$ & $(.451)$ & $2.85(0.33)$ & $(.024)^{*}$ \\
\hline \multicolumn{8}{|l|}{ Years of work experience } \\
\hline$<2$ & $59(80.8)$ & $3.30(0.55)$ & 0.555 & $3.27(0.39)$ & -0.621 & $3.16(0.47)$ & 0.762 \\
\hline$\geq 2$ (years) & $12(16.4)$ & $3.14(0.59)$ & $(.581)$ & $3.34(0.18)$ & $(.537)$ & $3.05(0.41)$ & $(.449)$ \\
\hline \multicolumn{8}{|l|}{ Type of work-shift } \\
\hline No-shift work & $15(20.5)$ & $3.12(0.52)$ & -1.199 & $3.27(0.29)$ & -0.091 & $2.93(0.37)$ & -2.046 \\
\hline 3-shift & $58(79.5)$ & $3.31(0.55)$ & $(.235)$ & $3.28(0.28)$ & $(.928)$ & $3.20(0.46)$ & $(.044)^{*}$ \\
\hline \multicolumn{8}{|l|}{ Working department } \\
\hline ER & $19(26.0)$ & $3.26(0.53)$ & 2.139 & $3.28(0.31)$ & 1.530 & $3.18(0.40)$ & 0.763 \\
\hline ICU & $26(35.6)$ & $3.41(0.46)$ & $(.104)$ & $3.25(0.35)$ & $(.215)$ & $3.19(0.45)$ & $(.519)$ \\
\hline OR \& Anes & $13(17.8)$ & $3.36(0.63)$ & & $3.47(0.43)$ & & $3.19(0.57)$ & \\
\hline Ward/outpatient/others & $15(20.5)$ & $2.98(0.55)$ & & $3.19(0.36)$ & & $2.98(0.43)$ & \\
\hline \multicolumn{8}{|l|}{ Working hospital type } \\
\hline Tertiary $^{\dagger}$ & $27(37.0)$ & $3.26(0.53)$ & -0.146 & $3.30(0.41)$ & 0.376 & $3.11(0.53)$ & -0.401 \\
\hline Primary \& secondary ${ }^{\dagger \dagger}$ & $46(63.0)$ & $3.28(0.57)$ & $(.884)$ & $3.27(0.34)$ & $(.708)$ & $3.16(0.41)$ & $(.690)$ \\
\hline \multicolumn{8}{|l|}{$\begin{array}{l}\text { Motivation for the } \\
\text { selection of nursing job }\end{array}$} \\
\hline Job stability (JS) & $35(47.9)$ & $3.33(0.52)$ & 1.105 & $3.17(0.44))$ & 1.923 & $2.96(0.28)$ & 4.676 \\
\hline Job expertise (JE) & $23(31.5)$ & $3.20(0.59)$ & $(.362)$ & $3.44(0.43)$ & $(.117)$ & $3.39(0.58)$ & $(.002)^{*}$ \\
\hline $\begin{array}{l}\text { Recommendation from } \\
\text { other people }\end{array}$ & $6(8.2)$ & $3.54(0.36)$ & & $3.32(0.44)$ & & $2.96(0.38)$ & $\begin{array}{l}\mathrm{JS}>\mathrm{TE} \\
(p=.011)\end{array}$ \\
\hline Scarcity of male nurses & $7(9.6)$ & $2.92(0.21)$ & & $3.24(0.21)$ & & $3.37(0.40)$ & \\
\hline
\end{tabular}

Note. PA : physician assistant, SD: standard deviation, $\dagger$ :except no response, ${ }^{*} p<.05$; ER: Emergency room, ICU: Intensive care unit, OR \& Anes: Operation room \& Anesthesiology, $\uparrow:$ tertiary-University hospital, $\uparrow+$ : primary and secondary- district hospital with over 300 beds, JS: Job stability, JE: Job expertise

Table 2. Correlation of job satisfaction with job stress and coping behaviour

\begin{tabular}{lll}
\hline & Job stress $\boldsymbol{r}(\boldsymbol{p})$ & Coping behavior $\boldsymbol{r}(\boldsymbol{p})$ \\
\hline \multirow{2}{*}{ Job satisfaction } & $r=-0.047$ & $r=0.426$ \\
& $(p=.702)$ & $(p<.001)^{*}$ \\
\hline
\end{tabular}

${ }^{*} p<.05$

Table 3. Differences in job satisfaction associated with levels of job stress and coping behaviour

\begin{tabular}{llll}
\hline variables & group & Job satisfaction score & $\mathbf{t}(\boldsymbol{p})$ \\
\hline \multirow{2}{*}{ Job stress } & Upper quartile score group $(\mathrm{n}=16)$ & $3.17(0.58)$ & 0.042 \\
& Lower quartile score group $(\mathrm{n}=17)$ & $3.17(0.53)$ & $(.967)$ \\
\multirow{2}{*}{ Coping behaviour } & Upper quartile score group $(\mathrm{n}=16)$ & $3.53(0.53)$ & -2.881 \\
& Lower quartile score group $(\mathrm{n}=19)$ & $3.09(0.37)$ & $(.007)^{*}$ \\
\hline${ }^{*} p<.05$ & & &
\end{tabular}




\section{Discussion}

This study was conducted to gain a better understanding of factors that could help improve the job satisfaction of male nurses in Korea. The increase in the number of male nurses has led to a greater ability to meet diverse nursing requirements, and improvement of nursing care standards. It is necessary to understand the factors associated with job satisfaction and dissatisfaction in order to increase the efficiency of male nurses and allow them to advance professionally.

Participants' mean scores on measures of job stress (3.27), coping behaviour (3.14), and job satisfaction (3.28) were all considered to be above the intermediate level (2.5). Among the participants' general characteristics, the following were related to the coping behaviour and job satisfaction: marital status, type of work, type of work-shift and motivation for the selection of nursing as a career.

A study by Li and Lambert (2008) ${ }^{[16]}$ showed that the education level of nurses, years of experience in nursing, and years of experience in the current area of work were the factors influencing workplace stress, coping methods, and job satisfaction. However, in this study, no difference was found in terms of age and years of experience. A study by Tzeng (2002) ${ }^{[27]}$ suggested that salaries, promotions, the institution, educational background, and age all influenced work motivation and job satisfaction. In this study, there was a difference based on the type of institution. A study by Lu et al. $(2007)^{[15]}$ showed that organizational, professional, and personal variables can influence job stress, coping behaviour, and job satisfaction. In this study, staff nurses showed higher job satisfaction than specialists and physician assistants in connection with the type of work, which implies that the role conflict ${ }^{[12,13]}$ between specialists and physician assistants - the majority of whom are male nurses in Korean hospitals - could have an influence. Additionally, those working on three rotating shifts were found to have higher job satisfaction than those not working on shifts, which is contrary to the results of previous studies ${ }^{[28,29]}$ that have raised concerns about shift work. In addition, those who were motivated by professionalism to select the nursing occupation showed high job satisfaction. Moreover, marital status influenced coping behaviour. As most previous studies investigated female nurses, the characteristics of male nurses have not been investigated extensively. It is important to consider various situations facing male nurses in order to gain insight into their job stress, coping behaviour, and job satisfaction.

Correlation analysis was conducted to determine how job stress and coping behaviour were related to job satisfaction. A positive correlation was found between job satisfaction and coping behaviour. In other words, greater coping behaviour was associated with greater job satisfaction. These results were consistent with those from the analysis of the job satisfaction scores based on coping-behaviour-score group membership. The group with higher coping behaviour scores had higher job satisfaction scores. Our results were similar to those of a study conducted by Teo, Pick, Newton, Yeung \& Chang (2013) ${ }^{[13]}$ which focused on clinical nurses, finding that the coping strategy of the organization could be a factor leading to the improvement of job satisfaction in this group. Pisanti $(2012)^{[30]}$ found that emotion-oriented coping affected job satisfaction among the coping strategies. The coping behaviour investigated in this study included various behaviours by individuals to cope with stress, such as problem-oriented coping behaviour, hope and positive standpoint-based coping behaviour, social support system-based coping behaviour, relaxation or exercise for releasing tension, and mood control.

A study by Zhou and Hong (2013) ${ }^{[31]}$ found that nurses preferred self-control as a coping strategy, while a study by Chen et al. (2009) ${ }^{[12]}$ showed that programs and initiatives related to self-esteem were necessary to map out and implement constructive stress coping strategies. Meanwhile, a study by Tyson, Pongruengphant, and Aggarwal (2002) ${ }^{[32]}$ showed that a positive correlation was observed between problem solving and job satisfaction. This shows that coping behaviour is a substantial factor that can influence job satisfaction. Thus, it is necessary to create an environment and culture within an organization that can help ensure that various coping methods can be applied by individuals.

However, job stress and job satisfaction were not found to be correlated in the current study. Furthermore, no difference was observed in job satisfaction score between score groups. These results are different from those of previous studies ${ }^{[33,34]}$ claiming that job stress and job satisfaction had either a negative or a positive correlation. To determine the 
systematic relationship among these variables, it will be necessary to examine the relationship among specific aspects of job stress and job satisfaction in studies that include larger samples.

\subsection{I mplications for clinical nursing}

The Korean nursing sector has recently seen growth in the number of male nurses, but the management and role of male nurses have not been closely examined. To increase the efficiency of male nurses and increase their professional success, it is necessary to create a new and expanded role for male nurses that is clear and well defined. Amidst these changes, healthcare administrators should be aware of factors related to job satisfaction among male nurses and provide opportunities for them to improve their knowledge and skills so as to increase their job satisfaction. In particular, it is necessary to design programs that can help increase job satisfaction in order to create an environment and culture that allows male nurses to cope with the stress arising from the work they perform. In order to manage this workforce efficiently, the administrators of hospitals and nursing departments need to develop programs to improve the coping capability of individuals and apply such programs to human resources management systems, rather than using one-sizefits-all education and training programs targeting all nurses.

\subsection{Study limitation}

The results of this study should be interpreted with care because male nurses in only two cities were included. Therefore, the generalizability of these results is limited. Future studies should attempt to replicate the current study using a greater number of subjects. Studies that succeed this one should also identify the unique characteristics of male nurses by comparing them to female nurses. In addition, it will be necessary to explore various cultural factors affecting the job satisfaction of male nurses.

\section{References}

[1] Wee H, Park Y, Song MS. High school boys' images of men as nurses. The Korean Journal of Fundamentals of Nursing. 2013; 20(2): 118-128. http://dx.doi.org/10.7739/jkafn.2013.20.2.118

[2] Korean nurse association. Male nurse. Available from: http://www.koreanurse.or.kr/ (accessed January 8, 2013)

[3] Sherrod B, Sherrod D, Rasch R. Men at work. Nursing Management. 2005; 36(10): 46-51. PMid:16210951

[4] Sullivan EJ. Men in nursing: The importance of gender diversity. Journal of Professional Nursing. 2000 ; $16(5)$ : $253-254$. PMid:11033931 http://dx.doi.org/10.1053/jpnu.2000.9455

[5] Chan ZC, Chan YT, Yu HZ, Law YF, Woo WM, Lam CT. An ethnographical study on the academic experiences of Chinese male nursing students. Nurse Education in Practice. 2013; Sep 12. PMid:24094820

[6] Choi SJ. Male Students' Lived Experience in the Female-dominant Nursing College. Journal of Qualitative Research. 2003; 4(1): $52-62$.

[7] Rajacich D, Kane D, Williston C, Cameron S. If they do call you a nurse, it is always a "male nurse": experiences of men in the nursing profession. Nursing Forum. 2013; 48(1): 71-80. PMid:23379398 http://dx.doi.org/10.1111/nuf.12008

[8] Burnett M. Men at work. Men in Nursing. 2007; 1(1): 40-49.

[9] Meadus RJ, Twomey JC. Men in nursing: making the right choice. The Canadian Nurse. 2007; 103(1): 13-16. PMid:17326582

[10] Rajapaksa S, Rothstein W. Factors that influence the decisions of men and women nurses to leave nursing. Nursing Forum. 2009; 44(3): 195-206. PMid:19691656 http://dx.doi.org/10.1111/j.1744-6198.2009.00143.x

[11] Zamanzadeh V, Azadi A, Valizadeh L, Keogh B, Monadi M, Negarandeh R. Choosing and remaining in nursing: Iranian male nurses' perspectives. Contemporary Nurse. 2013; 45(2): 220-227. PMid:24299250 http://dx.doi.org/10.5172/conu.2013.45.2.220

[12] Chen CK, Lin C, Wang SH, Hou TH. A study of job stress, stress coping strategies, and job satisfaction for nurses working in middle-level hospital operating rooms. Journal of Nursing Research. 2009; 17(3): 199-211. PMid:19738448 http://dx.doi.org/10.1097/JNR.0b013e3181b2557b

[13] Teo ST, Pick D, Newton CJ, Yeung ME, Chang E. Organizational change stressors and nursing job satisfaction: the mediating effect of coping strategies. Journal of Nursing Management. 2013; 21(6): 878-887. PMid:23890099

http://dx.doi.org/10.1111/jonm.12120 
[14] Golbasi Z, Kelleci M, Dogan S. Relationships between coping strategies, individual characteristics and job satisfaction in a sample of hospital nurses: cross-sectional questionnaire survey. International journal of nursing studies. 2008; 45(12): $1800-1806$. PMid:18703192 http://dx.doi.org/10.1016/j.ijnurstu.2008.06.009

[15] Lu H, While AE, Barriball KL. Job satisfaction and its related factors: a questionnaire survey of hospital nurses in Mainland China. International Journal of Nursing Studies. 2007; 44(4): 574-588. PMid:16962123 http://dx.doi.org/10.1016/j.ijnurstu.2006.07.007

[16] Li J, Lambert VA. Workplace stressors, coping, demographics and job satisfaction in Chinese intensive care nurses. Nursing in Critical Care. 2008; 13(1): 12-24. PMid:18226051 http://dx.doi.org/10.1111/j.1478-5153.2007.00252.x

[17] Yada H, Abe H, Omori H, Matsuo H, Masaki O, Ishida Y, Katoh T. Differences in job stress experienced by female and male Japanese psychiatric nurses. International Journal of Mental Health Nursing. 2014; Jun 3. PMid:24894127 http://dx.doi.org/10.1111/inm.12080

[18] Lou JH, Yu HY, Hsu HY, Dai HD. A study of role stress, organizational commitment and intention to quit among male nurses in southern Taiwan. Journal of Nursing Research. 2007; 15(1): 43-53. PMid:17370232 http://dx.doi.org/10.1097/01.JNR.0000387598.40156.d2

[19] Ahn KH, Seo JM, Hwang SK. Content analysis of male hospital nurses' experiences. Journal of Korean Academy of Adult Nursing. 2009; 21(6): 652-665.

[20] Son HM, Koh MH, Kim CM, Moon JH, Yu MS. The male nurses' experiences of adaptation in clinical setting. Journal of Korean Academy of nursing. 2003; 33(1): 17-25.

[21] An ES, Chu SK. Study on male nurses' gender stereotype and job satisfaction. Journal of Korean Academy of Nursing Administration. 2011; 17(1): 14-21. http://dx.doi.org/10.11111/jkana.2011.17.1.14

[22] Kim HJ. Job Stress and Satisfaction among Male Nurses in Daegu. Unpublished master thesis, Yeungnam University, Dae-gu, Korea, 2012.

[23] Chang SJ, Koh SB, Kang D, Kim SA, Kang MG, Lee CG, et al. Developing an occupational stress scale for Korean employees. Korean Journal of Occupational and Environmental Medicine. 2005; 17(4): 297-317.

[24] Han CS, Oh GS. Study on the grief and coping pattern of mothers who have a chronically ill child. Korean Nurse. 1990; 29(4): 73-88.

[25] Lasarus RS, Folkman S. Stress, appraisal and coping. New York. Springer. 1984.

[26] Slavitt DB, Stamps PL, Piedmont EB, Haase AM. Nurses' satisfaction with their work situation. Nursing Research. 1978; 27(2): 114-120. PMid:245630 http://dx.doi.org/10.1097/00006199-197803000-00018

[27] Tzeng HM. The influence of nurses' working motivation and job satisfaction on intention to quit: an empirical investigation in Taiwan. International Journal of Nursing Studies. 2002; 39(8): 867-878. http://dx.doi.org/10.1016/S0020-7489(02)00027-5

[28] Admi H, Tzischinsky O, Epstein R, Herer P, Lavie P. Shift work in nursing: is it really a risk factor for nurses' health and patients' safety? Nursing Economics. 2008; 26(4); 250-257. PMid:18777974

[29] Berger AM, Hobbs BB. Impact of shift work on the health and safety of nurses and patients. Clinical Journal Oncology Nursing. 2006; 10(4): 465-471. PMid:16927899 http://dx.doi.org/10.1188/06.CJON.465-471

[30] Pisanti R. Job demands-control-social support model and coping strategies: predicting burnout and wellbeing in a group of Italian nurses. La Medicina del lavoro. 2013; 103(6): 466-481.

[31] Zhou H, Gong YH. Relationship between occupational stress and coping strategy among operating theatre nurses in China: a questionnaire survey. Journal of Nursing Management. 2013; Aug 9. PMid:23927607 http://dx.doi.org/10.1111/jonm.12094

[32] Tyson PD, Pongruengphant R, Aggarwal B. Coping with organizational stress among hospital nurses in Southern Ontario. International Journal of Nursing Studies. 2002; 39(4): 453-459. http://dx.doi.org/10.1016/S0020-7489(01)00047-5

[33] Nam MH, Lee SH. Effect of jog stress and coping strategy on job satisfaction in a hospital works. Korean Journal of Occupational and Environmental Medicine. 2008; 15(1): 1-11.

[34] Cheng CY, Liou SR, Tsai HM, Chang CH. Job stress and job satisfaction among new graduate nurses during the first year of employment in Taiwan. International Journal of Nursing Practice 2014; Mar 26. http://dx.doi.org/10.1111/ijn.12281 